\title{
Saberes em viagem nos manuais pedagógicos: construções da escola em Portugal e no Brasil (1870-1970)
}

\author{
Vivian Batista da Silva \\ Universidade São Francisco, Programa de Mestrado em Educação
}

\section{Os manuais pedagógicos e as construções da escola em Portugal e no Brasil}

O intuito do presente trabalho é construir, numa perspectiva sócio-histórico-comparada, uma história dos manuais pedagógicos publicados em Portugal e no Brasil, desde a edição dos títulos mais antigos dos quais se tem conhecimento, na década de 1870 , até o século seguinte, quando foi notável o uso mais recorrente de fotos, ilustrações, capas coloridas, letras maiores, enfim, um conjunto de técnicas editoriais que configuraram outras modalidades de escritos e motivaram práticas de ler pouco freqüentes até aquele momento. Os alunos da Escola Normal usaram os manuais para estudar pela primeira vez as questões relativas ao ofício de ensinar, junto às disciplinas pedagogia, didática, metodologia e prática de ensino, encontrando nesses textos os saberes a partir dos quais conceberam sua profissão. Ao pretender dar conta dos modos pelos quais esses títulos - juntamente com outras instâncias relativas, por exemplo, à legislação ou aos regulamentos - participaram da construção de uma cultura escolar (Chervel, 1990; Julia, 1995;
Escolano, 1999), o texto aqui apresentado discute em que medida os livros dos normalistas colaboraram para a consolidação do tipo de escola conhecido em diversas partes do mundo, e procura evidenciar dois aspectos intimamente relacionados. Por um lado, analisa como esse material foi criado no interior de projetos de formação de um número significativo de professores para ensinarem em instituições públicas mantidas pelo Estado, e destinado a todos de forma gratuita e obrigatória. Por outro lado, examina os manuais pedagógicos como instâncias de produção e circulação dos saberes que fundamentaram esse modelo de ensino. Assim, a história dos manuais articulou-se à difusão mundial da escola e dos conhecimentos pedagógicos.

Enquanto um dos resultados das iniciativas que corporificaram a escola e um lugar de elaboração de conhecimentos sobre essa instituição e suas práticas, os manuais pedagógicos permitem examinar aspectos importantes da constituição da cultura escolar. O conceito é especialmente útil no estudo dos manuais porque, conforme enfatiza Chervel (1990), permite atentar para as especificidades do modo de funcionamento da instituição e do trabalho dos professores. 
Além disso, ao considerar a idéia a partir de Dominique Julia, é possível remeter, primeiramente, para as normas a partir das quais são concebidos os conteúdos e comportamentos a serem ensinados aos alunos. Tais normas são explicitadas nos manuais dos professores, já que, segundo Julia (1995), elas não podem ser analisadas sem levar em conta a categoria profissional dos agentes que deverão seguir essas ordens. Em segundo lugar, a idéia de cultura escolar assinala as práticas que permitem a transmissão desses saberes. Isso significa considerar que os manuais pedagógicos, ao dirigirem-se aos professores, elaboram e divulgam os conhecimentos a partir dos quais a cultura escolar é construída. Mas talvez valha a pena considerar outras questões decorrentes dos possíveis usos desse conceito. Num texto no qual situa e analisa as idéias de diversos autores acerca do tema, Diana Vidal (2005) retoma o conceito tal como ele é pensado por Augustín Escolano (1999), ao distinguir três culturas da escola. Uma delas é chamada de empírica, prática ou material, sendo produzida cotidianamente pelos docentes; a outra é a política ou normativa, ou seja, corresponde às regras que governam o funcionamento das escolas; e, por fim, há uma cultura do tipo científica ou pedagógica, elaborada, segundo o autor, para explicar ou propor modos de trabalho tipicamente escolares. Os saberes dos manuais referem-se justamente a essa última modalidade, ocupando um lugar específico na dinâmica de construção da cultura escolar.

Além disso, ao comparar produções portuguesas e brasileiras, o que se quer é analisar o espaço de produção desses livros, pois se eles colaboraram de alguma maneira para a constituição mundial da cultura escolar, foi inevitável examinar em que lugar do mundo eles foram escritos. Ou seja, houve a necessidade de conhecer espaços determinados, nos quais os conhecimentos educacionais foram dados a ler e que, portanto, evidenciaram a dinâmica internacionalmente estabelecida de contato e troca de experiências, além das possíveis variáveis desse processo em diferentes espaços. Foi possível, assim, ultrapassar o estudo de questões internas a um âmbito nacional, abrangendo lugares mais amplos onde as idéias circularam (Catani, 2000). Dito de outro modo, o movimento internacional de informações foi tomado aqui como um processo incorporado de forma específica por portugueses e brasileiros. Integrando o chamado mundo lusófono constituído basicamente por Portugal e suas ex-colônias -, esses países aproximaram-se por questões políticas e culturais, permitindo "imaginar comunidades de sentido, emergentes da partilha de um mesmo espaço lingüístico" (Nóvoa, 2000, p. 126). A exemplo de Anderson (1989), a lusofonia foi considerada resultado da construção de uma comunidade imaginada. Nessa perspectiva, portugueses e brasileiros compuseram elos lingüísticos e históricos imaginados porque, embora nem todos os membros de cada lado do oceano pudessem se conhecer pessoalmente, em suas mentes habitou (e ainda habita) a imagem de um passado e língua comuns. E, não obstante as desigualdades características das relações entre Portugal e Brasil durante o período colonial, houve uma certa fraternidade entre os dois países. Mas o sentido de comunidade entre portugueses e brasileiros não se constituiu de forma idêntica à de uma nação, limitada por fronteiras mais finitas e um sentimento de união mais forte. Os laços nacionais sempre foram tomados no sentido de um companheirismo profundo e horizontal, evidenciado na partilha de um mesmo território, língua e cultura. Como assinalou Burke (2002), o termo comunidade obrigou a pensar o fato de cada grupo ter sido permeado por solidariedades elaboradas e reconstruídas no decorrer do tempo, e não por atitudes homogêneas ou livres de conflitos.

No âmbito das iniciativas educacionais, Portugal e Brasil foram tomados como casos de "atraso". Tal "impropriedade" dos pensamentos brasileiro e português, como foi concebida durante certo tempo por alguns autores, em várias "teorias" de inspirações marxistas ou liberais, produzidas no âmbito da sociologia, foi notável também nos manuais pedagógicos, cujos escritores partiram das referências ao "mundo desenvolvido" para explicar as realidades dos países tidos como "subdesenvolvidos". Esses esforços acabaram por desconsiderar as diferenças entre as socie- 
dades tidas como "atrasadas" e as dos países "centrais", e postular a existência de uma continuidade que supostamente iria do subdesenvolvimento ao desenvolvimento. Entretanto, essa interpretação é analisada aqui em outro sentido, de modo que se destaque o fato de ter sido social e historicamente construída. As estruturas "dependentes" não foram meros reflexos de outras mais "adiantadas", eles tiveram sua própria dinâmica no interior dos limites definidos pelas relações de dominação-subordinação entre os países. Essa perspectiva de análise justificou a importância da idéia dos saberes viajantes, porque os conhecimentos educacionais foram traduzidos nas mais diversas partes do mundo, incorporando uma pluralidade inerente a eles. A suposição do "atraso educacional" português e brasileiro não resultou, então, de uma impropriedade inerente aos pensamentos elaborados nesses espaços, mas, antes, de uma hierarquia criada entre os países "mais" e os "menos" modernos. Nessa perspectiva, a lógica da expansão da escola pelo mundo classificou os países ora como "exemplos de modernidade" a serem seguidos, ora como grupos a quem coube aprender como organizar seus sistemas de ensino a partir das lições oferecidas pelos países "mais modernos", classificação muitas vezes ligada a questões de ordem econômica. Envergonhando a uns, irritando a outros educadores da época, a suposta posição atrasada de seus países foi um argumento poderoso e incorporado ao discurso educacional português e brasileiro. Certamente, essa lógica de apropriação foi visível nos manuais pedagógicos, favorecendo determinadas formas de produção e circulação de saberes educacionais.

A articulação de conhecimentos que fundamentaram a criação e expansão da escola já mobilizou estudos na área durante os anos de 1930; entretanto, os historiadores tenderam a rejeitar a comparação, alegando estarem interessados no estudo das particularidades de um lugar determinado (Burke, 2002). Nos últimos anos, houve uma retomada do interesse pela comparação em história, a partir do reconhecimento de que a escola tornou-se possível pela diversidade e de que, assim, foi possível também conhecer o que esteve presente (ou não) nos diferentes espaços, assinalando a importância de uma ausência específica (idem, p. 40). Para além do conhecimento de histórias paralelas, esse esforço exigiu a elaboração de explicações acerca das proximidades e distâncias entre nações (Catani, 2000). Foram justamente as relações entre a parte e o todo, manifestadas na incorporação local de discursos mundialmente difundidos acerca da escolarização, que puderam ser evidenciadas mediante o estudo comparado de duas realidades educacionais. De fato, o desafio de comparação aqui assumido não visou estabelecer dicotomias, encontrando experiências tidas como "mais avançadas" ou outras como "mais atrasadas", mas quis compreender o modo como diferentes práticas discursivas se relacionaram, configurando determinadas maneiras de pensar e agir. Tal como foi proposta aqui, a análise dos manuais pedagógicos inseriu-se no quadro de investimentos mais amplos, na busca de objetos de pesquisa e metodologias de trabalho capazes de contribuir para uma renovação na abordagem comparada em história da educação em língua portuguesa, perspectiva na qual é possível construir uma análise socioistórico-comparada dos manuais pedagógicos escritos em Portugal e no Brasil desde 1870 até 1970.

Procurando reunir em escritos aparentemente sintéticos as questões tidas como essenciais para os educadores, tanto os autores dos manuais portugueses quanto os autores dos manuais brasileiros citaram escritos de pedagogos, filósofos, sociólogos, psicólogos, biólogos e outros cientistas para definirem as funções docentes, os papéis dos alunos e os métodos de ensino. Quando mencionaram, explicaram ou resumiram diversas idéias, essas pessoas exerceram papel fundamental nas redes de comunicação estabelecidas entre os chamados "teóricos" e os professores, em suas práticas cotidianas. Os manuais mediaram assim a compreensão do pensamento educacional, expondo aos normalistas algumas informações que essas pessoas ainda não tinham lido ou entendido. Por isso, foi inerente a esses livros certo tom didático ou professoral. Os textos citaram autores, livros, revistas; explicaram o quanto determinadas ciências pu- 
deram ser úteis para a pedagogia ou situaram as iniciativas educacionais levadas a efeito em várias partes do mundo. Desse modo, a circulação de saberes ocorreu basicamente nas relações com o "Outro", quando os manuais articularam conhecimentos do campo pedagógico com os de outras áreas, bem como as informações originadas no país onde os títulos foram publicados com outras provindas de diferentes partes do mundo. Esse movimento de idéias caracterizou a escrita dos manuais e construiu os vários componentes do modelo escolar, ou seja, os professores, a instituição, os alunos, os métodos de ensino. Isso porque a articulação entre diversos conhecimentos permitiu justificar as proposições de trabalho dessa instituição.

Esse movimento de saberes, caminhando ou, como se poderia dizer também, viajando de um lugar para outro, favoreceu o uso de diversas referências na elaboração de conhecimentos pedagógicos. Quando determinadas obras foram divulgadas - e outras esquecidas -, estiveram em jogo questões relacionadas ao prestígio de certos nomes entre os professores, bem como determinações de ordem econômica, relativas ao interesse das editoras na propaganda de certos títulos. Os saberes moveram-se de um lugar e período determinados para outros, e transformaram-se nesse caminho, de acordo com as múltiplas situações em que se apresentaram. Cada trajeto percorrido por essa e outras teorias envolveu diferentes leituras nos vários locais nos quais foram conhecidos, criando diferenças relativas às idéias tal como foram originalmente escritas. Desse modo, a circulação de saberes é uma questão nuclear, pois só foi possível conhecer as configurações dos conteúdos dos manuais tomando-as como articulações entre diferentes conhecimentos, a partir das quais saberes específicos dos livros dos normalistas foram criados, de modo que explicassem questões relativas à vida escolar ou propusessem determinadas práticas de ensinar. Ao constituírem-se como vias de circulação de conhecimentos pedagógicos, nas quais foram apresentadas determinadas idéias aos futuros professores, os textos em pauta colaboraram para a construção e difusão das instituições de ensino e das formas pelas quais elas foram concebidas.

Os saberes usados nos manuais puderam ser comparados a fios de uma corda discursiva (Nóvoa, 2000), elaborada ao longo do tempo e graças à comunicação existente entre diferentes espaços. Essa metáfora sugeriu, nos limites do presente trabalho, o princípio segundo o qual as diversas interpretações de um pensamento comportaram elementos de continuidade: o entrelaçamento de uma corda só foi possível graças aos fios já existentes, a partir dos quais outros entrelaçamentos foram possibilitados. Entretanto, ao reentrelaçar-se, a corda assumiu novas configurações, adquirindo outros significados, o que sugeriu o fato de a expansão mundial da escola ter sido um processo relativamente homogêneo e que, simultaneamente, assumiu contornos específicos em espaços determinados (Nóvoa \& Schriewer, 2000). E os modos pelos quais "a melhor geração pedagógica de sempre" (Nóvoa, 1995, p. 26) foi dada a ler diferiram no decorrer dos anos e no interior de diversos lugares. Nessa perspectiva, as redes de comunicação assumiram dimensões muito amplas, atingindo escalas nacionais, internacionais e mundiais. Por essa razão, foi preciso pensar aspectos da expansão da escola desde o século XIX, evidenciando o quanto isso multiplicou os intercâmbios entre diferentes países, campos de saberes e profissionais interessados nas questões pedagógicas. Os professores entraram em contato permanente com outras idéias e experiências, as quais constituíram um corpo de conhecimentos mundialmente compartilhados e, assim, amplos, fluidos e plurais. Os manuais pedagógicos foram um dentre outros veículos usados nesse processo, com o qual colaboraram também as revistas de ensino, os jornais especializados e outros tipos de escritos sobre educação (Catani, 1994). Palavras e enunciados das mais variadas naturezas puderam circular, desde explicações científicas acerca da criança, justificativas para o uso de determinado método didático, definições para o papel do professor e da escola, até prescrições minuciosas sobre como agir em sala de aula. Nesses termos, as constituições dos manuais para professores e 
da escola resultaram de conexões estabelecidas em diversas partes do mundo.

Do mesmo modo, a expansão mundial das instituições de ensino e dos conhecimentos pedagógicos envolveram simultaneamente as nações, os grupos e os indivíduos. Isso favoreceu, por um lado, uma história desse movimento totalizante, relacionado com a expansão do capitalismo nos séculos XV-XVIII, a formação dos Estados-nação, o advento das sociedades industriais e a modernidade, aspectos intimamente relacionados com a construção da escola (Meyer, Ramirez \& Soysal, 1992). No final do século XX, cristalizou-se um conjunto de fenômenos sociais, políticos e educacionais que transcendeu as nações e os povos. Esses fenômenos permitiram a autores como Meyer, Ramirez e Soysal (1992) e Schriewer (2001) assinalarem um processo de "difusão mundial da escola". Nesse sentido, foram notáveis as observações de autores como Chervel (1990) e Dominique Julia (1995) acerca de uma cultura escolar histórica e socialmente construída. Tal como a própria escola, os professores e alunos, os processos de ensino e aprendizagem e os materiais didáticos (dos quais claramente se destacaram aqui os manuais para professores) tiveram uma história e uma tradição de pensamento e vocabulário que lhe deram realidade e presença no e para o sistema escolar mundialmente difundido. Tanto o modelo de escola como os manuais para professores, desse modo, se apoiaram e se refletiram mutuamente. A história dos livros dos normalistas foi construída a partir de uma espécie de tríade formada por esses textos, a escola e os saberes educacionais, ou seja, o intuito foi evidenciar os manuais como um produto das iniciativas que corporificaram a escola, ao mesmo tempo em que produziram essa realidade, pois foram lugares nos quais os saberes sustentadores desse modelo circularam e foram elaborados.

\section{Os livros dos normalistas}

Os manuais pedagógicos, tanto em Portugal como no Brasil, tiveram o ensino como seu objeto de ensino, produzindo uma espécie de gramática do magis- tério e articulando os elementos para conceber e agir nesse ofício. Os livros da Escola Normal foram escritos durante a constituição de sistemas de ensino públicos, obrigatórios, gratuitos e organizados pelo Estado. Os investimentos não se dirigiram, nessa perspectiva, à formação de um único discípulo, mas ampliaram-se para o povo, e por isso os manuais pedagógicos vincularam-se aos projetos de expansão da escola. ${ }^{1}$ Esses títulos foram usados desde o século XIX nas mais diversas partes do mundo: em Portugal, no Brasil (Villela, 2000) e em outros países como a França (Chopin, 2002; Roullet, 1998) e a Espanha (Fernández \& Salvado, 1998; Pintado, 2000), onde houve esforços para democratizar as oportunidades escolares. Tais impressos foram leitura obrigatória, sobretudo entre aquelas pessoas que não tiveram acesso a graus mais elevados de instrução e que, para ingressarem na carreira docente, limitaram seus estudos ao âmbito das Escolas Normais ou do preparo para admissão na carreira do magistério. Os manuais foram, nesse sentido, produtos da escola feita para o povo, ao mesmo tempo em que explicaram a composição dos elementos da vida nessa instituição. Embora não seja possível retomar aqui os conteúdos do total de 80 títulos localizados, dos quais 25 são portugueses e 55 são brasileiros, convém retomar alguns exemplos que permitam compreender as formas pelas quais esses livros tiveram o ensino como seu objeto de ensino.

Uma primeira característica a ser assinalada é o fato de esses manuais terem sido escritos para aqueles que trabalharam no plano mais elementar da escolarização básica, em que os anseios de expansão das oportunidades foram mais presentes. Em Pedagogia sociológica II, Lima (1936) expôs de forma muito clara as diferenças entre os diversos níveis de ensino, evidenciando o caráter mais democrático do nível primário e o caráter mais seletivo dos outros graus. Em seu entender, as funções e relações da escola de $1^{\circ}$ ciclo, ou edu-

${ }^{1}$ Os próprios alunos da escola primária contaram com livros que desenvolveram os conteúdos do currículo e que já mobilizaram importantes trabalhos na área da história da educação (Bittencourt, 1993; Gatti Jr., 2004; Batista, 1999, Munakata, 1999). 
cação primária, com a escola de nível médio e universitário definiram-se a partir de três critérios:

A) Critério que considera o $1^{\circ}$ ciclo como inteira ou quase inteiramente independente do fim ou ideal social da educação, contendo em si próprio a sua finalidade. Neste caso, o $1^{\circ}$ ciclo é apenas formal. Resume-se num instrumento de aperfeiçoamento subjetivo, e, portanto, nada tem com os intuitos da Educação dos outros ciclos $\left(2^{\circ}\right.$ e $\left.3^{\circ}\right)$. O seu fim é apenas dar instrumentos para uma futura cultura. Esses instrumentos são: ler, escrever e contar.

B) Critério que inclui o $1^{\circ}$ ciclo na finalidade ou ideal a alcançar pela Educação e considera-o como a primeira fase da sua gradação, devendo, por conseguinte, obedecer ao ideal geral adotado, como objetivo supremo, por essa Educação. Neste caso, o $1^{\circ}$ ciclo ou Educação da infância é uma parte de um todo; é uma parte convergente para um mesmo fim. Presta auxílio e contribui, pelo esforço conjugado, para o êxito final, para a realização do ideal comum de todos os graus da Educação. Constitui a parte inferior, o alicerce do todo, do edifício da educação. É uma preparação serventuária, indispensável para os graus ou ciclos subseqüentes.

C) Critério que integra a educação da infância no objetivo ou ideal supremo e geral da organização da Educação, mas considera-a também como devendo constituir, simultaneamente, só por si, um todo, uma habilitação social. (Lima, 1936, p. 236-237)

Em perspectiva semelhante, todos os manuais estudados produziram e fizeram circular saberes sobre o ofício de ensinar, tomando-os como temas a serem explicados durante as aulas nas Escolas Normais. De fato, as questões ligadas à educação mobilizaram estudos produzidos por psicólogos, sociólogos, biólogos ou filósofos, apenas para citar alguns exemplos. Mas as áreas que responderam mais diretamente às interrogações postas pelo magistério foram a pedagogia, a didática, a metodologia e a prática de ensino, cujo desenvolvimento foi profundamente relacionado com a construção da docência como profissão (Nóvoa, 1987). Isso conduziu, no interior do presente trabalho, a definir os manuais pedagógicos como os textos que expuseram aos normalistas os conteúdos das disciplinas mais especializadas em ensino, e que foram estudadas pelos futuros professores primários.

Tanto em Portugal como no Brasil, a maioria dos manuais foi editada apenas uma vez. E no caso de reedições os livros apresentaram pouca ou nenhuma alteração, vinculando-se quase que exclusivamente às exigências dos regulamentos dos programas dos cursos de formação de professores. Isso permitiu estabelecer pares de títulos publicados em diferentes momentos espaços, e essa vizinhança decorreu também, e principalmente, de movimentos que foram semelhantes no decorrer da história da formação docente nos dois países. Assim, se o marco inicial do estudo dos livros dos normalistas foram as décadas finais do século XIX, o intuito foi identificar os primeiros títulos publicados e marcar o fato de que essas edições se articularam aos esforços de formação sistemática de professores que, tanto no Brasil como em Portugal, começaram a estruturar-se via concursos de ingresso na carreira e também pelas Escolas Normais, criadas nesse período em ambos os países. Manuais como o Compêndio de pedagogia (Sá, 1870), os Elementos de pedagogia (Afreixo \& Freire, 1870) e as Noções elementares de pedagogia (Baganha, 1878) descreveram tópicos previstos para os concursos. Baganha (1878), por exemplo, escreveu seu manual porque ajudou suas irmãs a prestar concurso de ingresso na carreira docente, embora esse escritor tenha sido formado na área de pecuária. Os dois manuais brasileiros publicados na época também versaram sobre a pedagogia. Pontes (1881) escreveu o compêndio para ser usado pelos seus alunos da Escola Normal de Niterói a partir do programa de 1869 , marcado pela preocupação em descrever aos normalistas não apenas os conteúdos da escola primária (relativos à leitura, gramática, escrita e doutrina cristã, aritmética, história sagrada, antiga, média e moderna), como também a forma de ensiná-los. Essa ênfase articulou-se ao reconhecimento de que para lecionar foi preciso dominar os conteúdos e os seus modos de transmissão, compondo um modelo profissional diferenciado da imagem do antigo mestre-artesão, examinada por Villela (2000). 
Um segundo marco da história dos manuais pedagógicos foi mais ou menos coincidente em ambos os países e vinculou-se ao movimento da Escola Nova, durante as décadas iniciais do século XX. Esse foi um momento crucial para a legitimação da pedagogia nos dois países, e do magistério como profissão. Daí o esforço para garantir a esses cursos uma efetiva expansão do número de vagas e imprimir às Escolas Normais um caráter menos propedêutico e mais especializado. As disciplinas ditas pedagógicas ganharam mais espaço nos planos de estudos e tenderam a articularse com as ciências da educação (Nóvoa, 1987; Tanuri, 2000), o que explicou não só a proliferação de manuais pedagógicos escritos no período como também certo aprimoramento das temáticas já expressas nos títulos, que denotaram um tom "cientificizado", inédito até então. Tomando como referência os saberes relativos à infância, os manuais do período deixaram de destacar tanto as questões relativas ao professor quanto à organização da escola, como ocorreu anteriormente. Os textos da Escola Normal fundamentaram-se, então, em trabalhos de psicólogos, médicos, sociólogos, higienistas, biólogos, filósofos e outros especialistas da sociedade e da infância. A cultura pedagógica foi pensada para valorizar as características do educando, que foram objeto de explicação para os professores porque, na época, as finalidades escolares se dirigiram à educação integral das crianças, de suas atitudes, suas disposições e seus comportamentos. Lourenço Filho, por exemplo, em seu famoso Introdução ao estudo da Escola Nova (1930), assinalou como as tentativas de compreensão do desenvolvimento das crianças foram levadas a efeito em vários países desde os últimos anos do século XIX. Além de realizar estudos, houve esforços relativos às mudanças de procedimentos de ensino, marcando as diferenças entre uma escola chamada de antiga ou tradicional, e outra, diferente, nova. Essa polarização foi sistematicamente exposta nos livros dos normalistas.

Um terceiro marco expressou o processo correntemente denominado pelos estudiosos da área como sendo o de tecnicização do ensino, segundo a qual os professores foram tomados como funcionários do Es- tado. Isso explicou, em boa parte, a redução, em ambos os países, dos planos de estudos das Escolas Normais depois dos anos de 1940, e uma tendência crescente (até pelo menos os anos de 1970) caracterizada por uma espécie de receituário de ensino, acompanhada de uma especialização cada vez maior da didática. Depois dos anos de 1940 e 1950, aproximadamente, o escolanovismo deixou de ser um tema privilegiado nos manuais brasileiros e portugueses e os escritos caracterizaram-se por argumentos mais sintéticos, prescritivos, desenvolvidos em parágrafos mais curtos e usando frases de fácil entendimento. As configurações assumidas pela pedagogia e pela didática em Portugal foram expressas por Evangelista (1944) e Gaspar e Ferreira (1944), quando eles transcreveram os tópicos dos programas em seus manuais, destacando a ênfase dada aos fins educativos e aos meios (práticos) de alcançá-los. No Brasil, a didática foi mais enfatizada do que a pedagogia, e apareceu definida "como arte, ciência e direção da aprendizagem e mais a consciência do sentido das mesmas, que é a obtenção de um tipo desejável de comportamento do educando" (Nérici, 1972, p. 41, grifos do original).

Dessa forma, os manuais pedagógicos permitiram conhecer alguns dos modos pelos quais as questões ligadas ao ensino se configuraram ao longo do tempo. A análise do conteúdo e dos argumentos veiculados nos manuais pedagógicos no decorrer de um século evidenciou as combinações entre os elementos da relação pedagógica estabelecidas de formas múltiplas e dinâmicas. Sem esse esforço não teria sido impossível criar certo "consenso" em torno da imagem de escola como o melhor e único sistema de ensino existente (Tyack, 1974), muito visível depois da metade do século $\mathrm{XX}$, quando os manuais já trataram do professor, do modelo escolar graduado, do aluno e dos meios tidos como mais eficazes para alcançar o ensino e a aprendizagem. As características dos livros da Escola Normal e as várias iniciativas a partir das quais eles foram produzidos corresponderam, portanto, a aspectos essenciais para compreender a historicidade desses textos e os modos pelos quais eles contribuíram para a construção da idéia que hoje temos de escola. 


\section{A ênfase no moderno}

Os manuais pedagógicos assumiram como paradigmas de explicação as referências consideradas "mais desenvolvidas". Essas modalidades de experiências e produções foram tomadas como padrões de medida para avaliar o desempenho dos países tidos como "atrasados", supondo a existência de lições a serem aprendidas do exterior e a possibilidade de assim se poder transformar uma situação de defasagem numa outra de desenvolvimento. $\mathrm{O}$ atraso em termos educacionais foi exposto nos livros dos normalistas como um fator intimamente relacionado com as questões econômicas e políticas. Isso porque se acreditou que essa situação desfavorável decorreu, em boa parte, da necessidade de estruturar os sistemas de ensino, idealizados como instrumentos úteis ao progresso das nações e boa formação de seus cidadãos (Meyer, Ramirez \& Soysal, 1992; Sica \& Prechel, 1981).

Os manuais pedagógicos enfatizaram os países “adiantados" e, nessa perspectiva, as questões políticas e econômicas também apareceram associadas aos "progressos" alcançados nesses lugares em termos educacionais. Assim, os livros dos normalistas classificaram dois tipos de sociedades, aquelas "desenvolvidas" ou "modernas", de um lado, e as "subdesenvolvidas" ou "atrasadas", de outro. Quando começaram a ser publicados em Portugal e no Brasil, esses livros basearam-se nas produções e experiências que, como se acreditou, indicaram o caminho para construir escolas para o povo capazes de fortalecerem o espaço nacional e criar condições para os países competirem no sistema internacional moderno.

Para ilustrar essa tendência, convém retomar as palavras de António Leitão (1903), ao afirmar a necessidade de "recorrer ao estrangeiro para [...] guiar e colher a maior soma de conhecimentos, perante a pobreza de livros portugueses sobre a especialidade..." (não-paginado).

Se o ensino foi, portanto, um fenômeno amplo, e suas referências constituíram-se a partir das relações estabelecidas entre os países, convém saber como o sistema mundial foi dado a ler nos manuais da Escola Normal. A análise das mais de 30 mil referências constantes nos livros dos normalistas evidenciou quais modalidades de classificação eles fizeram dos diferentes espaços nacionais: a primeira, relativa aos lugares onde se reconheceu o nascimento e desenvolvimento inicial do modelo escolar, a Europa Ocidental; a segunda, referente a outro importante espaço de expansão da escolarização, a América do Norte, sobretudo os Estados Unidos; e, por fim, o grupo de nações que, segundo os manuais, não atingiram os benefícios do ensino, estando assim à margem do centro do circuito moderno. As produções dos países "atrasados" também foram lembradas, mas isso foi mais notável depois dos anos de 1950, momento em que o modelo de escolarização foi muito disseminado entre os países "pobres" (Meyer, Ramirez \& Soysal, 1992) e, portanto, os seus postulados já haviam sido incorporados nos discursos.

As numerosas citações a um nome, associadas à permanência dessa prática ao longo do tempo, bem como à sua dispersão nas páginas dos vários manuais publicados, foram indícios relevantes. Uma pequena recorrência de citações ou a sua concentração num único manual foram sinais de pouca ênfase dada a determinada referência. Essas foram operações graças às quais os textos das normalistas sintetizaram a bibliografia utilizada, fazendo circular saberes tidos como "essenciais" para o exercício do magistério. Então, para além da prática de assinalar a biografia dos nomes mencionados, houve incursões sobre as idéias de determinados autores, esforço a partir do qual os manuais cumpriram a sua principal função, elaborando e fazendo circular os saberes com os quais a escola foi concebida.

Assim, mesmo subordinando-se aos programas da Escola Normal, os manuais não deixaram de produzir conhecimento: partindo do já dito, eles instituíram formulações relativamente inéditas. Ora, os temas para estudo estiveram previstos e, de certo modo, isso não dependeu da vontade dos escritores. Mas eles responsabilizaram-se pelo detalhamento desses temas, e esse foi o espaço para a produção de saberes relati- 
vamente novos. A construção de alguns paradigmas também foi visível nos manuais pedagógicos. Entre os anos finais do século XIX e o início do século XX, nas páginas desses livros foram privilegiadas as questões relativas ao papel do professor e à organização da escola (matrícula dos alunos, condições do prédio, modelos de aula etc.), o que pode ser explicado pelo fato de que esse foi um momento inicial de ordenação dos sistemas escolares em cada país. Uma vez estabelecido um "consenso" em torno das questões relativas à escola e ao professor, os manuais dos anos de 1910 e 1920 passaram a versar predominantemente sobre os saberes acerca do aluno e da criança, de modo que encontrassem caminhos mais favoráveis à aprendizagem. Num terceiro momento, foi muito evidente a progressiva especialização das metodologias de ensino, quando houve uma espécie de retorno do tom prescritivo assumido pelos manuais de fins do século XIX, mas que se configurou de uma outra forma, pois as questões de organização da escola estiveram, de certa forma, resolvidas, assim como também se percebeu o aluno/a criança como um ser cujas potencialidades deveriam ser respeitadas. Agora, o intuito foi garantir a eficácia dos instrumentos utilizados para ensinar.

O exame dos manuais possibilitou, portanto, um entendimento das formas pelas quais algumas realidades foram construídas e dadas a ler. Provavelmente, os processos aqui investigados podem motivar o desenvolvimento de outras pesquisas, atentas, por exemplo, aos modos como os normalistas usaram seus compêndios. Se o trabalho analisou a viagem dos saberes nos manuais pedagógicos, é porque essa metáfora conduziu à questão nuclear do trabalho aqui desenvolvido, mostrando as articulações entre a construção da escola de massas e determinadas modalidades de leitura realizadas nos manuais da Escola Normal. Essa foi uma história de práticas de leitura feitas entre os educadores, pelas quais foram elaboradas as representações do professor e de seu lugar nas instituições de ensino conhecidas nas mais diversas partes do mundo.

\section{Manuais pedagógicos citados}

AFREIXO, José Maria; FREIRE, Henrique. Elementos de pedagogia. Lisboa: Tipografia do Futuro, 1870.

BAGANHA, Domingos. Noções elementares de pedagogia. Porto: Cruz Coutinho, 1878.

EVANGELISTA, Domingos. Elementos de pedagogia. Porto: Livraria Figueirinhas, 1944.

GASPAR, José Maria; FERREIRA, Orbelino. Notas de didática especial. Lisboa: U.B. Amaral, 1944.

LEITÃO, António. Lições de pedagogia. Coimbra: Tipografia França Amado, 1903.

LIMA, Adolfo. Pedagogia sociológica II. Porto: Livraria Escolar Progredidor, 1936.

LOURENÇO FILHO, Manoel. Introdução ao estudo da Escola Nova. São Paulo: Melhoramentos, 1930.

NÉRICI, Imídeo. Ensino renovado e ensino fundamental. São Paulo: Nobel, 1972.

PONTES, Antônio M. Silva. Compêndio de pedagogia. Niterói: Tipografia do Fluminense, 1881.

SÁ, António. F. M. Compêndio de pedagogia. Lisboa: Tipografia Portuguesa, 1870.

\section{Referências bibliográficas}

ANDERSON, Benedict. Nação e consciência nacional. São Paulo: Ática, 1989.

BATISTA, Antônio Augusto Gomes. Um objeto variável e instável: textos, impressos e livros didáticos. In: ABREU, Márcia (Org.). Leitura, história e história da leitura. Campinas: Mercado de Letras/Associação de Leitura do Brasil; São Paulo: FAPESP, 1999. p. 529-575.

BITTENCOURT, Circe. Livro didático e conhecimento histórico: uma história do saber escolar. Tese (Doutorado em Educação) Faculdade de Educação, Universidade de São Paulo, São Paulo, 1993.

BURKE, Peter. História e teoria social. São Paulo: Editora da UNESP, 2002.

CATANI, Denice Barbara. Distâncias, vizinhanças, relações. In: NÓVOA, António; SCHRIEWER, Jürgen (Eds.). A difusão mundial da escola. Lisboa: Educa, 2000. p. 143-150.

Ensaios sobre a produção e circulação dos saberes pedagógicos. Tese (Livre-docência) - Faculdade de Educação, Universidade de São Paulo, São Paulo, 1994. 
Saberes em viagem nos manuais pedagógicos

CHERVEL, André. História das disciplinas escolares. Teoria e Educação, Porto Alegre, n. 6, p. 117-229, 1990.

CHOPIN, Alain. L'histoire du livre et de l'édition scolaires: vers un état des lieux. Paedagogica Historica, Bélgica, Universitaire Stichting van België, v. XXXVII, n. 1, p. 21-50, fev. 2002. ESCOLANO, Augustín. Los profesores en la historia. In: MAGALHÃES, Justino; ESCOLANO, Augustín. Os professores na história. Porto: Sociedade Portuguesa de Ciências da Educação, 1999. p. 15-28.

FERNÁNDEZ, N.; SALVADO, J. Los libros y guías para el maestro. In: BENITO, Agustín Escolano (Dir.). Historia ilustrada del libro escolar en España de la posguerra a la reforma educativa. Madrid: Fundación Germán Sánchez Ruipérez, 1998. p. 439-468. GATTI JR., Décio. A escrita escolar da história - livro didático e ensino no Brasil (1970-1990). Bauru: EDUSC, 2004.

JULIA, Dominique. La culture scolaire comme objet historique. Paedagogica Histórica, International Journal of the History of Education, Suppl. Series, v. I, p. 353-382, 1995.

MEYER, John; RAMIREZ, F.; SOYSAL, Y. World expansion of mass education, 1870-1980. Sociology of Education, v. 65, n. 2, p. 128-149, abr. 1992.

MUNAKATA, Kazumi. Livro didático: produção e leituras. In: ABREU, Márcia (Org.). Leitura, história e história da leitura. Campinas: Mercado de Letras/Associação de Leitura do Brasil; São Paulo: FAPESP, 1999. p. 577-594.

NÓVOA, António. Le temps des professeurs. Lisboa: INIC, 1987. . Uma educação que se diz nova. In: CANDEIAS, António; NÓVOA, António; FIGUEIRA, Manuel Henrique. Sobre a educação nova: cartas de Adolfo Lima a Álvaro Viana de Lemos (1923-1941). Lisboa: Educa, 1995. p. 25-41.

. Tempos da escola no espaço Portugal-BrasilMoçambique: dez digressões sobre um programa de investigação. In: NÓVOA, António; SCHRIEWER, Jürgen. (Eds.). A difusão mundial da escola. Lisboa: Educa, 2000. p. 121-142.

NÓVOA, António; SCHRIEWER, Jürgen (Eds.). A difusão mundial da escola. Lisboa: Educa, 2000.

PINTADO, Antonio Morelo. Los manuales de historia de la educación y la formación de los maestros (1900-1930). Historia de la educación, Revista Interuniversitaria, Universidad de Salamanca, n. 19, p. 121-139, 2000.

ROULLET, Michèle. Manuels de pédagogie et de psychologie des écoles normales en France entre 1880 et 1920. These (Docteur) Université de Genève, Genève, 1998.
SCHRIEWER, Jürgen. Formas de externalização no conhecimento educacional. Lisboa: Educa, 2001.

SICA, Alan; PRECHEL, Harland. National political-economic dependency in the global economy and educational development. Comparative Education Review, p. 384-402, out. 1981.

TANURI, Leonor. História da formação de professores. Revista Brasileira de Educação, n. 14, p. 61-88, maio/ago. 2000.

TYACK, David B. The one best system - a history of American urban education. Cambridge, Massachusetts, Londres: Harvard University Press, 1974.

VIDAL, Diana Gonçalves. Culturas escolares: estudos de práticas de leitura e escrita na escola pública primária (Brasil e França, final do século XIX). Campinas: Autores Associados, 2005.

VILLELA, Heloísa Oliveira da Silva. Da palmatória à lanterna mágica: a Escola Normal da Província do Rio de Janeiro entre artesanato e a formação profissional (1868-1876). Tese (Doutorado em Educação) - Faculdade de Educação, Universidade de São Paulo, São Paulo, 2000.

VIVIAN BATISTA DA SILVA, doutora em educação pela Universidade de São Paulo (USP), é professora do Programa de Mestrado em Educação da Universidade São Francisco (USF). Publicações recentes: Os manuais pedagógicos em Portugal e no Brasil, de 1870 a 1970: um estudo sobre a constituição do ensino como objeto de ensino (Revista de Educação Pública, v. 15, p. 137-150, 2006); em co-autoria com Denice Barbara Catani, Cynthia Pereira de Sousa e Paula Perin Vicentini, O que eu sei de mim: narrativas autobiográficas, história da educação e procedimentos de formação (Educação \& Linguagem, São Bernardo do Campo, v. 1, n. 1, p. 31-50, 2005); e em co-autoria com António Carlos da Luz Correia, Saberes em viagem nos manuais pedagógicos (Portugal-Brasil) (Cadernos de Pesquisa, São Paulo, v. 34, n. 123, p. 613-622, 2004). Projeto em andamento intitulado "Representações de infância e juventude na cultura escolar" e coordenado pela professora doutora Adair Nacarato (USF), com apoio financeiro da Fundação de Amparo à Pesquisa do Estado de São Paulo (FAPESP). Além disso, é integrante do grupo de pesquisa coordenado pela professora doutora Rosario Lugli (Universidade Federal Paulista UNIFESP) sobre "História e Sociologia da Profissão Docente". E-mail:vivianbs@yahoo.com e vivian.silva@saofrancisco.edu.br Recebido em outubro de 2006 Aprovado em fevereiro de 2007 